\title{
The impact of EEG in the diagnosis and management of patients with acute impairment of consciousness
}

\author{
Impacto do EEG no diagnóstico e conduta dos pacientes \\ com alteração aguda do estado da consciência
}

João A. G. Ricardo, Marcondes C. França Jr., Fabrício O. Lima, Clarissa L. Yassuda, Fernando Cendes

\begin{abstract}
Objectives: To assess the frequency of electroencephalogram (EEG) requests in the emergency room (ER) and intensive care unit (ICU) for patients with impairment of consciousness (IC) and its impact in the diagnosis and management. Methods: We followed patients who underwent routine EEG from ER and ICU with IC until discharge or death. Results: During the study, 1679 EEGs were performed, with 149 (8.9\%) from ER and ICU. We included 65 patients and 94 EEGs to analyze. Epileptiform activity was present in 42 (44.7\%). EEG results changed clinical management in $72.2 \%$ of patients. The main reason for EEG requisition was unexplained IC, representing $36.3 \%$ of all EEGs analyzed. Eleven (33\%) of these had epileptiform activity. Conclusion: EEG is underused in the acute setting. The frequency of epileptiform activity was high in patients with unexplained IC. EEG was helpful in confirming or ruling out the suspected initial diagnosis and changing medical management in $72 \%$ of patients.
\end{abstract}

Key words: emergency EEG, impaired of consciousness, emergency room, intensive care unit.

\section{RESUMO}

Objetivo: Avaliar a frequência de exames de eletroencefalograma (EEG) solicitados no pronto-socorro (PS) e na unidade de terapia intensiva (UTI) em pacientes com rebaixamento do nível de consciência, bem como seu impacto no diagnóstico e na conduta. Métodos: Acompanhamos pacientes submetidos ao EEG do PS e da UTI com rebaixamento do nível de consciência até a alta ou óbito. Resultados: Realizamos 1679 EEGs no período de estudo; destes, 149 (8,9\%) foram solicitados no PS e na UTI. Incluímos 65 pacientes e 94 EEGs para análise; destes, 42 (44,7\%) apresentavam atividade epileptiforme. O EEG mudou a conduta em $72 \%$ dos pacientes. A razão principal para solicitação do EEG foi rebaixamento do nível de consciência de origem inexplicável (36,3\% dos EEGs). Destes, 33\% tinham atividade epileptiforme. Conclusão: Embora o EEG seja pouco usado em condições agudas, a frequência de atividade epileptiforme foi alta nos pacientes com rebaixamento do nível de consciência de origem inexplicável. O EEG foi decisivo para o esclarecimento diagnóstico e implicou mudança da conduta em $72 \%$ dos pacientes.

Palavras-Chave: EEG de emergência, rebaixamento de consciência, pronto-socorro, unidade de terapia intensiva.

With the advent of neuroimaging techniques, such as high resolution MRI, PET and SPECT, the importance of the electroencephalogram (EEG) in cerebral disease studies had decreased. However, nowadays, it has received high attention as an important source of information, especially in situations such as unexplained impairment of consciousness ${ }^{1-3}$, since it may offer valuable real time information about brain activity, which can be decisive in some life-threatening situations, as convulsive status epilepticus (CSE) and nonconvulsive status epilepticus (NCSE), in which early recognition and immediately treatment may not only prevent death, but also offer better outcomes ${ }^{1-8}$. It might also give important clues in the diagnosis of certain conditions, such as encephalitis, hypoxic-anoxic brain injury, metabolic disturbances, intoxication and structural lesions ${ }^{2,3,9-12}$.

In the present study, we aimed to assess the frequency of emergent EEG (eEEG) requests and its impact for both diagnosis and patients' management in order to investigate the necessity of 24-hours EEG service for both emergency room (ER) and intensive care unit (ICU) in a tertiary hospital.

Department of Neurology, Medical School, State University of Campinas (UNICAMP), Campinas SP, Brazil.

Correspondence: Fernando Cendes; Department of Neurology; FCM/UNICAMP; Cidade Universitária; $13083-970$ Campinas SP - Brasil;

E-mail:fcendes@unicamp.br

Support: Dr. JAGR received a scholarship from CAPES.

Conflict of interest: There is no conflict of interest to declare.

Received 09 August 2011; Received in final form 20 August 2011; Accepted 29 August 2011 


\section{METHODS}

\section{Subjects selection}

We included all patients with impairment of consciousness (drowsiness, confusional states or coma) from ER and general ICU for whom an eEEG was requested. Patients were enrolled between May 2008 and June 2009 and followed during hospitalization at UNICAMP university hospital. Exclusion criteria were age under 18 years old, patients in hospital wards and patients with poor quality EEG.

The study was approved by the local ethics committee.

\section{Clinical and epidemiological data}

Information was collected through personal interview and/or review of the medical chart. The analyzed variables were age, gender, Glasgow Coma Scale (GSC), presence of focal neurological signs on admission, as well as prior history of seizures, epilepsy and stroke. We also recorded the etiology of the acute neurological condition that prompted admission and patient management after eEEG.

During hospitalization, we followed the clinical course and outcomes until discharge or death.

\section{EEG analysis}

eEEG was defined as any EEG performed on an emergency basis ${ }^{13}$, as well as requested for immediate performance or during non business hour?

Each eEEG was performed on an analogical Nihon Khoden Acquisition System using a 16 channel and scalp electrodes placed according to the International 10-20 System of Herbert Jasper ${ }^{14}$. The EEG recording lasted from thirty minutes to two hours. We used 5 montages according American Clinical Neurophysiology Society (ACNS) guidelines ${ }^{15}$, as followed: longitudinal bipolar (double banana); transverse bipolar (coronal); longitudinal-transverse bipolar and two referential montages (including Average and Vertex $\mathrm{Cz}$ ).

Epileptiform activity was defined as spike or sharp waves with asymmetrical transient having a fast rising phase and a slower descending phase followed or not by a slow wave ${ }^{2}$.

Patients underwent manual opening and closure of the eyes, as well as auditive and painful stimulation.

Each EEG was evaluated by board certified neurophysiologists and later reviewed by both authors (JAGR and FC) in order to standardize criteria (Table 1).
For each patient, we recorded initial diagnostic hypothesis and final diagnosis. We compared these data and identified those individuals whose eEEG findings motivated changes in medical management, such as adjustment of antiepileptic drug dosage (AED) and indication for sequential EEG.

\section{Statistical analysis}

We used chi-squared or Fisher's exact tests to compare categorical variables among subgroups of patients. Statistical significance was considered at $\alpha$ of $5 \%$. Statistical analysis was performed using SYSTAT software (Systat Software, version 12.0, Chicago, IL, USA).

\section{RESULTS}

During the study period, a total of 1679 EEGs were performed by our EEG laboratory, including routine, hospital wards, emergency room and ICU. Of these, 149 (8.9\%) were performed as emergent EEG and 20 (13.4\%) performed by other services (they were not from ER or ICU), which were not included. Ninety four EEGs from the ER and ICU were analyzed (Fig 1).

Those 94 emergent EEGs were performed on 38 (58.5\%) men and 27 (41.5\%) women. Age ranged from 18 to 91 years (mean $55.7 ; \pm 17.9$ ). Nearly $25 \%$ had focal signs and $16.7 \%$ had a previous history of epilepsy. The average of GCS was 8.8 ( \pm 3.6$)$, with most of the patients $(50.8 \%)$ with a GCS under 8 .

The most common diagnoses in our cohort were cerebrovascular diseases (ischemic and hemorrhagic stroke, aneurism and sinus venus thrombosis) in 17 (26.2\%) patients, brain trauma injury (BTI) in $8(12.3 \%)$ and central nervous system (CNS) tumor in 5 (7.7\%). Overall, half of the patients presented seizures on admission. Those early seizures were more frequent among patients with cerebrovascular diseases (Table 2).

\section{Presenting characteristics of EEG}

The number of EEGs performed for each patient ranged from 1 to 6; most of these (53.3\%) were performed after 24 hours of admission. In 89 EEGs, activation methods were performed. Manual opening and closure of the eyes did not reveal any reactivity in 39 (43.8\%), painful stimulus did not reveal any EEG reactivity in 33/87 (37.9\%), and auditive stimulus did

Table 1. Operational definitions for EEG findings.

\section{Epileptiform activity}

Focal epileptiform activity

Generalized epileptiform activity

Triphasic waves

PLED/BiPLED

Diffuse slowing

Focal slowing

Low voltage

Burst-suppression

Electrocerebral inactivity
Presence of sharp wave, spikes, with or not preceded by slow wave

Epileptiform activity well localized in a hemisphere or lobe

Epileptiform activity generalized, symmetric and synchronous

Delta waves, positive wave preceded and followed by negative waves

Periodic lateralized epileptiform discharge and bilateral independent PLED

Delta or theta waves diffusely distributed

Delta or theta waves localized in a hemisphere or lobe

Slow waves with amplitude less than 20 microvolts

Paroxysmal activity alternating with periods of suppression of EEG

Isoelectric EEG recording 
not reveal any reactivity in 44/87 (50.6\%). The main EEG abnormalities found in this cohort are shown in Fig 2.

The main reason underlying indication of the eEEG was not clear in 3 medical requests. Most of the remaining EEGs were requested to investigate impairment of consciousness or status epilepticus (convulsive or non-convulsive). Other reasons for medical request were herpetic encephalitis, myoclonus evaluation and management of AED. Among the 33 EEGs that were indicated due to unexplained impaired of consciousness, 11 (33.3\%) had epileptiform activity (Table 3).

Comparison of the initial diagnostic and final diagnosis hypothesis showed that the EEG confirmed the hypothesis in 36 (39.6\%), the EEG ruled out the diagnosis in 30 (32.9\%) and was not helpful in 25 (27.5\%). After EEG acquisition, patient management changed in 66 (72.5\%), for example, as showed in Fig 3 and 4.

\section{Outcomes predictors}

Twenty six (40\%) patients died in our cohort. Fatal outcome was more frequent among patients who developed hemodynamic complications $(57.1 \%)$, electrolytic $(63.5 \%)$ disturbance, sepsis $(39.7 \%)$ or renal failure $(68.3 \%)$ (Table 4$)$.

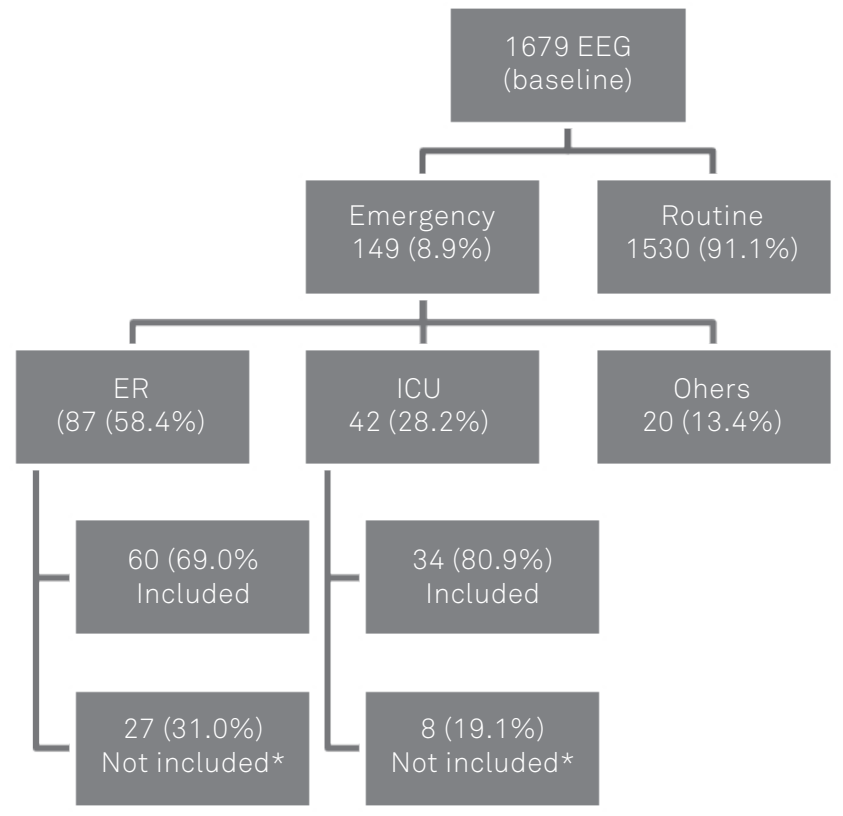

*Number of exams was not included in the study due to technical reasons.

Fig 1. Flowchart showing the number of EEGs performed in electroencephalography service.

Table 2. Initial diagnosis, history of seizures and EEG epileptiform abnormalities on admission and outcomes.

\begin{tabular}{|c|c|c|c|c|}
\hline Initial diagnosis & $\begin{array}{l}\text { No of patients } \\
\text { (percentage) }\end{array}$ & Seizures on admission & Epileptiform activity & $\begin{array}{l}\text { Outcomes } \\
\text { (death) }\end{array}$ \\
\hline Aneurysm & $3 / 65(4.62)$ & $2 / 3(66.70)$ & $1 / 3(33.3)$ & $0 / 3(0.00)$ \\
\hline Alcohol withdrawal & $2 / 65(3.08)$ & $1 / 2(50.00)$ & $1 / 2(50.0)$ & $0 / 2(0.00)$ \\
\hline Hemorrhagic stroke & $3 / 65(4.62)$ & $1 / 3(33.30)$ & $2 / 3(66.7)$ & 1/3 (33.33) \\
\hline Ischemic stroke & $8 / 65$ (12.31) & $6 / 8(75.00)$ & $3 / 8(37.5)$ & $5 / 8(62.50)$ \\
\hline Stomach cancer & $1 / 65(1.54)$ & $0 / 1(0.00)$ & $0 / 1(0.0)$ & $1 / 1(100.00)$ \\
\hline Convulsive seizure & $1 / 65(1.54)$ & $1 / 1(100.00)$ & $0 / 1(0.0)$ & $0 / 1(0.00)$ \\
\hline Encephalitis & $3 / 65(4.62)$ & $2 / 3(66.67)$ & $1 / 2(50.0)$ & 1/3 (33.33) \\
\hline Anoxic Encephalopathy & 4/65 (6.15) & $1 / 4(25.00)$ & $1 / 4(25.0)$ & $2 / 4(50.00)$ \\
\hline Epilepsy & 4/65 (6.15) & 4/4 (100.00) & $2 / 4(50.0)$ & $2 / 4(50.00)$ \\
\hline Schizophrenia & $1 / 65(1.54)$ & $0 / 1(0.00)$ & $0 / 1(0.0)$ & $0 / 1(0.00)$ \\
\hline Chronic liver disease & $2 / 65(3.08)$ & $0 / 2(0.00)$ & $0 / 2(0.0)$ & $1 / 1(100.00)$ \\
\hline AMI & $1 / 65(1.54)$ & $0 / 1(0.00)$ & $0 / 1(0.0)$ & $1 / 1(100.00)$ \\
\hline $\mathrm{CHF}$ & $1 / 65(1.54)$ & $0 / 1(0.00)$ & $0 / 1(0.0)$ & $1 / 1(100.00)$ \\
\hline CNS infection & $2 / 65(3.08)$ & $0 / 2(0.00)$ & $2 / 2(100.0)$ & $1 / 2(50.00)$ \\
\hline Exogenous intoxication & $2 / 65$ (3.08) & $0 / 2(0.00)$ & $1 / 2(50.0)$ & $0 / 2(0.00)$ \\
\hline CJD & $1 / 65(1.54)$ & $0 / 1(0.00)$ & $1 / 1(100.0)$ & $1 / 1(100.00)$ \\
\hline SLE & $1 / 65(1.54)$ & $1 / 1(100.00)$ & $1 / 1(100.0)$ & $1 / 1(100.00)$ \\
\hline $\mathrm{NHL}$ & $1 / 65(1.54)$ & $0 / 1(0.00)$ & $0 / 1(0.0)$ & $1 / 1(100.00)$ \\
\hline Ataxia telangiectasia & $1 / 65(1.54)$ & $1 / 1(100.00)$ & $0 / 1(0.0)$ & $1 / 1(100.00)$ \\
\hline Dementia & $2 / 65(3.08)$ & $0 / 2(0.00)$ & $2 / 2(100.0)$ & $0 / 2(0.00)$ \\
\hline Sepsis & $1 / 65(1.54)$ & $0 / 1(0.00)$ & $0 / 1(0.0)$ & $1 / 1(100.00)$ \\
\hline Superior vena cava occlusion & $1 / 65(1.54)$ & $1 / 1(100.00)$ & $0 / 1(0.0)$ & $1 / 1(100.00)$ \\
\hline AIDS & $1 / 65(1.54)$ & $1 / 1(100.00)$ & $1 / 1(100.0)$ & $0 / 1(0.00)$ \\
\hline BTI & $8 / 65(12.31)$ & 4/8 (50.00) & $3 / 8(37.5)$ & $3 / 8(37.50)$ \\
\hline Cerebral sinus thrombosis & $3 / 65(4.62)$ & $3 / 3(100.00)$ & $0 / 3(0.0)$ & $1 / 3(33.33)$ \\
\hline CNS tumor & $5 / 65(7.69)$ & $3 / 5(60.00)$ & $2 / 5(40.0)$ & $0 / 5(0.00)$ \\
\hline Liver transplantation & $1 / 65(1.54)$ & $0 / 1(0.00)$ & $1 / 1(100.0)$ & $0 / 1(0.00)$ \\
\hline Mielodysplasic syndrome & $1 / 65(1.54)$ & $1 / 1(100.00)$ & $0 / 1(0.0)$ & $0 / 1(0.00)$ \\
\hline
\end{tabular}

AMI: acute myocardial infarction; CJD: Creutzfeldt-Jakob disease; SLE: systemic lupus eritemathous; NHL: non-Hodgkin's lymphoma; BTI: brain traumatic injury; CNS: central nervous system; CHF: congestive heart failure; AIDS: acquired immune deficiency syndrome. 


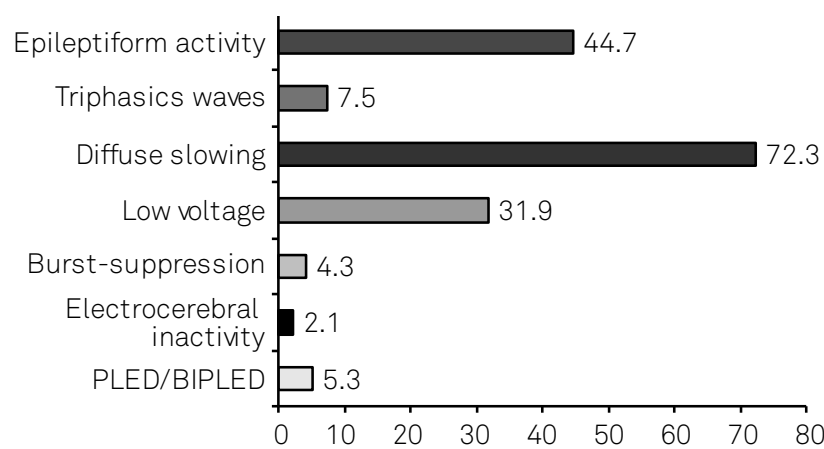

Fig 2. EEG findings in percentage of patients.

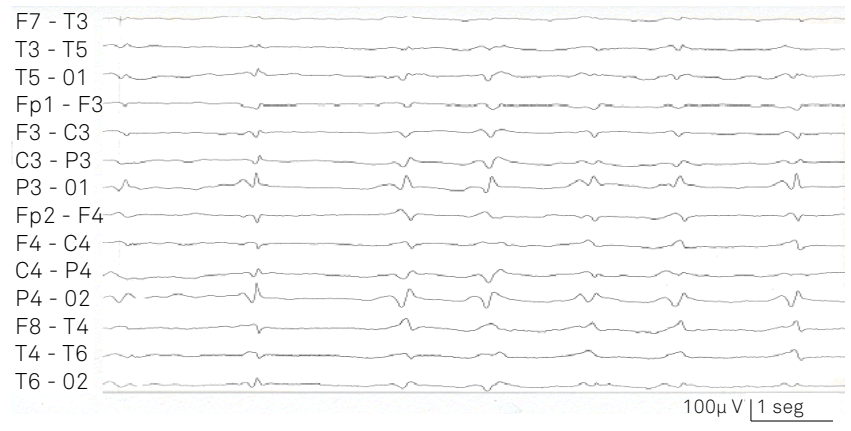

Fig 3. An EEG of a 67 years old male, one month of history characterized by alteration of behavior, little contact with environment, rigidity. EEG showing periodic complexes with short intervals. The presence of this pattern conducted an investigation of Creutzfeldt-Jakob disease which was confirmed after necropsy.

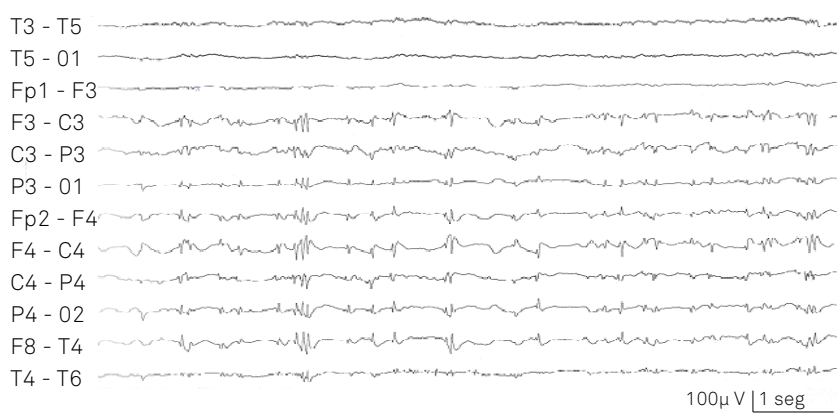

Fig 4. An EEG of a 66 years old male, obtained from a patient after surgery for basocellular carcinoma of face. EEG showing continuous focal sharp and polyspike activity in right hemisphere alternating with suppression periods (burstsuppression). Clinically, patient presented in coma and oral automatisms, without sedation, for four days.

Table 3. Reasons of medical requests for emergent EEG and frequency of epileptiform activity.

\begin{tabular}{lccc} 
& \multicolumn{2}{c}{ Epileptiform activity } & \multirow{2}{*}{ Total } \\
\cline { 2 - 3 } Indication of EEG & No & Yes & \\
\cline { 2 - 3 } & $\mathrm{n}(\%)$ & $\mathrm{n}(\%)$ & $\mathrm{n}(\%)$ \\
\hline Unexplained impairment of & $22(66.7)$ & $11(33.3)$ & $33(100)$ \\
consciousness & $2(66.7)$ & $1(33.3)$ & $3(100)$ \\
Herpetic encephalitis & $14(46.7)$ & $15(53.3)$ & $29(100)$ \\
Status epilepticus & $0(0.0)$ & $2(100.0)$ & $2(100)$ \\
Myoclonic & $11(52.4)$ & $10(47.6)$ & $21(100)$ \\
NCSE & $2(66.7)$ & $1(33.3)$ & $3(100)$ \\
Management of AED & &
\end{tabular}

AED: antiepileptic drug; NCSE: nonconvulsive status epilepticus.
Reaction during manual eyes opening and closure was significantly more common in patients who survived (OR 5.3 $\mathrm{p}<0.05)$ (Table 4).

The GCS on admission was not associated with the outcome of patients $(p>0.05)$. Age, localization of the disease in the CNS, focal signs, non reactivity to auditive and painful stimulus were not associated with poor outcome (death) (Table 4).

\section{DISCUSSION}

Although EEG is not an expensive exam and it changes medical management as shown by several studies, its use is not available in most tertiary hospitals. We analyzed 94 EEGs ordered on emergency basis from patients with impairment of consciousness. Our study showed that a high proportion (44.7\%) of EEGs performed in patients with impairment of consciousness had epileptiform activity. The EEG changed management in $72.2 \%$ of the patients. By contrast, the proportion of EEGs ordered by ER and ICU was very low (8.9\%) relative to the number of exams performed in the EEG laboratory during the study period. The same pattern of underutilization of eEEG was reported in previous studies ${ }^{3,716}$. In developing countries, costs and the small number of specialized professionals (technicians and eletroencephalographers) are key issues ${ }^{13}$. In the other hand, many physicians do not believe that EEG will help or change the medical intervention, especially when neuroimaging is available. In our series, most EEGs were performed after 24 hours of admission (53.3\%), in contrast to a previous Indian study that reported that $84.3 \%$ of the EEGs were performed in less than 24 hours $^{13}$. This difficulty to have EEG on time often bring as consequence inappropriate treatment, in particular when there is a possibility of NCSE.

We found epileptiform abnormalities in almost half of our patients, comparable to another study ${ }^{17}$, but we think this is an underestimate for at least two reasons. First, most of the patients were taking sedatives, which are known to interfere with EEG recordings. Second, EEGs were performed on an analogical system that precluded the change of montages, sensibility and time scale that improves the chances of finding abnormal patterns ${ }^{18}$. The significance of epileptiform abnormalities in patients without history of epilepsy is unclear and may occur in up to $6.6 \%$ in some studies. However, the risk of seizure occurrence is two folds higher in the presence of interictal epileptiform discharges ${ }^{19}$.

In the last three decades, EEG had lost importance in the investigation of cerebral diseases, but several studies have shown the utility of EEG in conditions other than epilepsy, including evaluation of prognosis in coma. In our study, the EEG confirmed the diagnosis in $39.6 \%$ of the cohort and ruled out in $32.3 \%$, being comparable with earlier studies ${ }^{3,13,16,17}$. 
Table 4. Predicting factors of prognosis.

\begin{tabular}{lccc} 
& \multicolumn{2}{c}{ Outcomes } & \multicolumn{2}{c}{ Chi-Square } \\
\cline { 2 - 4 } More 50 years old & Death (\%) & Alive (\%) & p value \\
Focal signs & $76.9(20 / 26)$ & $53.8(21 / 39)$ & 0.063 \\
Hemodynamic disturb. & $40(10 / 25)$ & $38.5(15 / 39)$ & 0.902 \\
Electrolytic disturb. & $76.9(20 / 26)$ & $41.7(15 / 36)$ & 0.007 \\
Renal failure & $88.5(23 / 26)$ & $33.3(12 / 36)$ & 0.0001 \\
Sepsis & $61.5(16 / 26)$ & $22.2(8 / 36)$ & 0.002 \\
CNS disease & $92.3(24 / 26)$ & $41.7(15 / 36)$ & 0.0001 \\
Epileptiform activity & $65.4(17 / 26)$ & $79.5(31 / 39)$ & 0.063 \\
Nonreactivity by passive eye opening & $23.1(6 / 26)$ & $46.2(18 / 39)$ & 0.004 \\
Nonreactivity by auditive stimulus & $57.7(15 / 26)$ & $22.2(8 / 36)$ & 0.116 \\
Nonreactivity by dolorous stimulus & $53.9(14 / 26)$ & $35.3(12 / 34)$ & 0.226 \\
\hline
\end{tabular}

CNS: central nervous system.

In our cohort, the most common reason for EEG requisition was to investigate unexplained altered level of consciousness (36.3\%), to evaluate convulsive status epilepticus (31.9\%) and nonconvulsive status epilepticus (23.1\%). In the last two conditions, EEG is the gold standard for diagnosis ${ }^{3,16,20}$. We encountered a higher proportion (33.3\%) of epileptiform activity in patients with unexplained altered level of consciousness. In an early study, status epilepticus was encountered in $37 \%$ of 198 patients with altered level of consciousness without clinical seizures ${ }^{21}$. Another study using continuous EEG observed status epilepticus in $8 \%$ of 236 comatose patients 5 . This last group of patients in our cohort did not have signs of subclinical status epilepticus or previous history of epilepsy. Despite of the absence of minor clinical signs of seizures, EEG showed abnormalities and permitted the correct diagnosis and treatment.

Although we had a small number of patients with stroke in this series, they had a high frequency of epileptiform activity on EEG (6/8; 75\%). Previous studies have shown an association between acute stroke and epilepsy ${ }^{22-25}$. In a review ${ }^{24}$, the prevalence of post-ischemic stroke seizures ranged from 2 to $33 \%$, with 50 to $78 \%$ of first seizures occurring within 24 hours. Another study ${ }^{6}$ found a high proportion of nonconvulsive and convulsive seizures in intracerebral hemorrhage (27.8\%) compared with ischemic stroke (6\%), and over half of traumatic brain injured patients had nonconvulsive seizures detected by continuous EEG monitoring, reinforcing literature data about the necessity of available EEG service at 24 hours for stroke and other ER and ICU patients especially in the acute phase.

The GCS were not different between groups of outcome, confirming that GCS has limited value except for impairment of consciousness related to head trauma ${ }^{26,27}$.

The main limitation of our study was the nature of data collection from medical charts to complete our database and the possibility of over or underestimating the data from charts and medical EEG request.

In conclusion, although eEEG is an underutilized diagnostic tool, the frequency of EEGs presenting epileptiform activity was high in patients with unexplained altered level of consciousness. In most cases, EEG proved to be useful, either confirming or ruling out the suspected initial diagnosis. The EEG makes the difference especially when available within 24 hours after admission. Therefore, we believe that ER and ICU physicians should be aware of the usefulness of EEG and request it more often in appropriate circumstances.

\section{ACKNOWLEDGMENTS}

We thank the medical staff and EEG technicians from the EEG service at University Hospital of UNICAMP.

\section{References}

1. Bauer G, Trinka E. Nonconvulsive status epilepticus and coma. Epilepsia 2010;51:177-190.

2. Niedermeyer E, Silva FHL. Electroencephalography: Basic principles, clinical applications and related fields. Mariland, USA: William \& Wilkins, 1999.

3. Praline J, Grujic J, Corcia P, et al. Emergent EEG in clinical practice. Clin Neurophysiol 2007;118:2149-2155.

4. Young GB, Jordan KG, Doig GS. An assessment of nonconvulsive seizures in the intensive care unit using continuous EEG monitoring: an investigation of variables associated with mortality. Neurology 1996;47: 83-89.
5. Towne AR, Waterhouse EJ, Boggs JG, et al. Prevalence of nonconvulsive status epilepticus in comatose patients. Neurology 2000;54:340-345.

6. Vespa PM, O'Phelan K, Shah M, et al. Acute seizures after intracerebral hemorrhage: a factor in progressive midline shift and outcome. Neurology 2003;60:1441-1446.

7. Quigg M, Shneker B, Domer P. Current practice in administration and clinical criteria of emergent EEG.J Clin Neurophysiol 2001;18:162-165.

8. Drislane FW, Lopez MR, Blum AS, Schomer DL. Detection and treatment of refractory status epilepticus in the intensive care unit. J Clin Neurophysiol 2008;25:181-186. 
9. Misra UK, Kalita J. Seizures in encephalitis: predictors and outcome. Seizure 2009;18:583-587.

10. Alroughani R, Javidan M, Qasem A, Alotaibi N. Non-convulsive status epilepticus; the rate of occurrence in a general hospital. Seizure 2009;18:38-42.

11. Kaplan PW. The EEG in metabolic encephalopathy and coma. J Clin Neurophysiol 2004;21:307-318.

12. Bahamon-Dussan JE, Celesia GG, Grigg-Damberger MM. Prognostic significance of EEG triphasic waves in patients with altered state of consciousness. J Clin Neurophysiol 1989;6:313-319.

13. Firosh Khan S, Ashalatha R, Thomas SV, Sarma PS. Emergent EEG is helpful in neurology critical care practice. Clin Neurophysiol 2005;116:2454-2459.

14. Duffy FH, lyer VG, Surwillo WW. Clinical electroencephalography and topographic brain mapping. New York: Spring-Verlag; 1989.

15. American Clinical Neurophysiology Society. Guideline 6: a proposal for standard montages to be used in clinical EEG. J Clin Neurophysiol 2006;23:111-117.

16. Varelas PN, Spanaki MV,Hacein-Bey L, HetherT, Terranova B. Emergent EEG: indications and diagnostic yield. Neurology 2003;61:702-704.

17. Kilbride RD, Costello DJ, Chiappa KH. How seizure detection by continuous electroencephalographic monitoring affects the prescribing of antiepileptic medications. Arch Neurol 2009;66:723-728.
18. Van Cott A, Brenner RP. Technical advantages of digital EEG. J Clin Neurophysiol 1998;15:464-475

19. So EL. Interictal epileptiform discharges in persons without a history of seizures: what do they mean? J Clin Neurophysiol 2010;27:229-238.

20. Claassen J, Mayer SA, Kowalski RG, Emerson RG, Hirsch LJ. Detection of electrographic seizures with continuous EEG monitoring in critically ill patients. Neurology 2004;62:1743-1748.

21. Privitera M, Hoffman M, Moore JL, Jester D. EEG detection of nontonic clonic status epilepticus in patients with altered consciousness. Epilepsy Res 1994;18:155-166.

22. Selim M, Kumar S, Fink J, Schlaug G, Caplan LR, Linfante I. Seizure at stroke onset: should it be an absolute contraindication to thrombolysis? Cerebrovasc Dis 2002;14:54-57.

23. Cohn HR, Mulder DW, Neumann MH. Cerebral vascular lesions: electroencephalographic and neuropathologic correlations. Arch Neurol 1948;60:163-181.

24. Camilo O, Goldstein LB. Seizures and epilepsy after ischemic stroke. Stroke 2004;35:1769-1775.

25. Burn J, Dennis M, Bamford J, Sandercock P, Wade D, Warlow C Epileptic seizures after a first stroke: the Oxfordshire Community Stroke Project. BMJ 1997;315:1582-1587.

26. Sternbach GL. The Glasgow coma scale.J Emerg Med 2000;19:67-71.

27. Segatore M, Way C. The Glasgow Coma Scale: time for change. Heart Lung 1992;21:548-557. 